Supporting information for

\title{
Band Structure Modification and Mass Fluctuation Effects of Isoelectronic Germanium-Doping on Thermoelectric Properties of ZrNiSn
}

Kishor Kumar Johari 1, 2*, Ruchi Bhardwaj'1, 2, Nagendra S. Chauhan³, Bhasker Gahtori 1, 2 *, Sivaiah Bathula ${ }^{1,2,4}$, Sushil Auluck ${ }^{1}$, S. R. Dhakate ${ }^{1,2}$

${ }^{1}$ CSIR-National Physical Laboratory, Dr. K.S. Krishnan Marg, New Delhi, 110012, India

${ }^{2}$ Academy of Scientific \& Innovative Research (AcSIR), CSIR-NPL Campus, New Delhi, 110012, India

${ }^{3}$ Department of Micro \& Nanofabrication, International Iberian Nanotechnology Laboratory (INL), Braga 4715 330, Portugal

${ }^{4}$ School of Minerals, Metallurgical and Materials Engineering, IIT Bhubaneswar, 752050, India

*Corresponding author: bhasker@nplindia.org; kishorjohari@gmail.com

Tel.: +91114560 8556; Fax: +911145609310

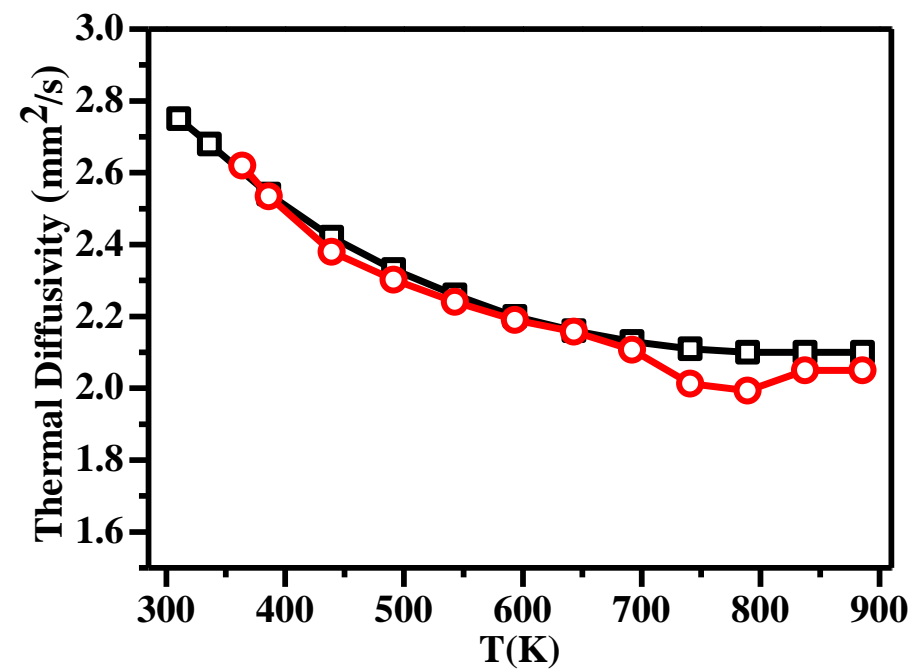

Fig. S1: Thermal diffusivity measurement repeatability of ZrNiSn.
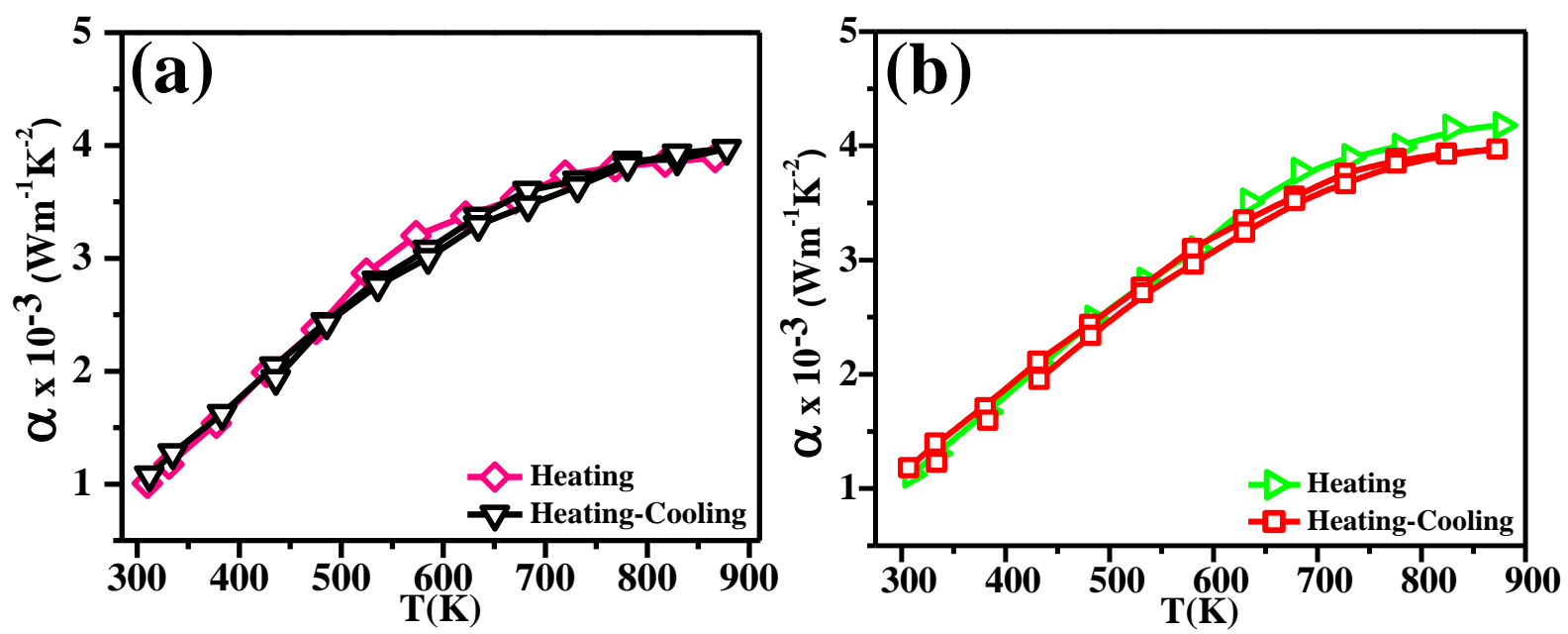

Fig. S2: Power factor measurement repeatability of $\mathrm{ZrNiSn}_{1-\mathrm{x}} \mathrm{Ge}_{\mathrm{x}}$, (a) $\mathrm{x}=0.02$, (b) $\mathrm{x}=0.03$. 